\title{
THE MECHANICS OF BREATHING IN NEWLY BORN BABIES
}

\author{
BY
}

\author{
M. B. MCILROY AND E. S. TOMLINSON
}

From the Medical Professorial Unit and Children's Department, St. Bartholomew's Hospital, London

(RECEIVED FOR PUbliCATION OCTOBER 6, 1954)

Little is known about the mechanics of breathing in newborn babies. The difficulties encountered in obtaining spirometric tracings in infants have largely been surmounted by the use of a body plethysmograph (Shaw and Hopkins, 1931 ; Murphy and Thorpe, 1931 ; Cross, 1949 ; Boutourline-Young and Smith, 1950), and in the past 20 years the normal range of infants' tidal volume has been established. Up to now, however, no measurements of the intrathoracic pressure have been reported and no attempt has been made to measure the work required to ventilate the lungs. This paper reports a study of the mechanics of breathing in newly born babies in whom the mechanical work of breathing has been measured from simultaneous tracings of the intraoesophageal pressure and air flow in a manner similar to that already reported in adults by McIlroy, Marshall, and Christie (1954).

\section{MeTHODS}

The intra-oesophageal pressure was measured by the method described by Dornhorst and Leathart (1952). A sterile polythene tube of $1 \mathrm{~mm}$. bore was passed via the nose until the tip lay in the thoracic oesophagus about 10 to $15 \mathrm{~cm}$. from the nares. The tube was filled with water and the pressure at the tip recorded electrically by means of a capacitance manometer. It has already been shown by Dornhorst and Leathart (1952) and Fry, Stead, Ebert, Lubin, and Wells (1952) in adults and by Mead and Whittenberger (1953) in experimental animals that the intraoesophageal pressure reflects changes in intrathoracic pressure accurately. The volume of air breathed was measured by means of a body plethysmograph of the type described by Cross (1949). The apparatus, which is shown in Fig. 1, consisted of a rigid box with a side tube $2.5 \mathrm{~cm}$. in diameter to which a pneumotachograph was connected. A perspex lid was clamped on the box over a layer of sponge rubber, and the baby lay in the box with its face projecting through an oval hole in the lid. An air-tight seal was obtained between the baby's face and the perspex lid by means of an inflatable soft rubber cuff.

The pneumotachograph was of the type described by Lilly (1950) with a 400 -mesh screen of 5 sq. $\mathrm{cm}$. area. The relationship between the pressure drop across the screen and air flow was linear at flow rates of up to 10 litres per-minute, so that the volume of air passing could be calculated by measuring the area under the flow curve or by electrical integration using a condenser-resistance network. The pressure difference between the two sides of the pneumotachograph screen was recorded electrically using a capacitance manometer, the output being fed into a double beam cathode ray oscillograph together with the electrical signal representing the intra-oesophageal pressure. A tracing of intra-oesophageal pressure and air flow or tidal volume was obtained with a recording camera.

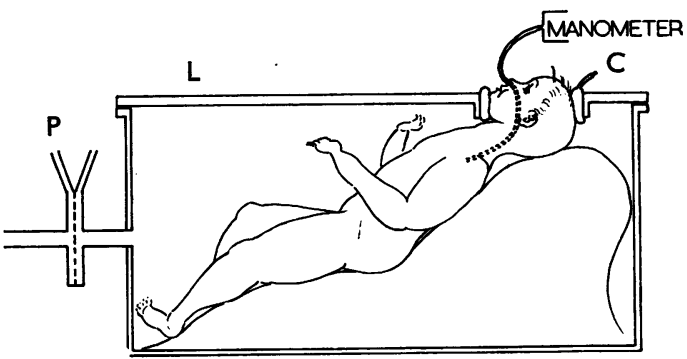

FIG. 1.-Diagram of body plethysmograph. L, perspex lid; C, inflatable rubber cuff; $\mathbf{P}$, pneumotachograph.

The flow tracings obtained using the body plethysmograph did not reflect accurately the changes in air flow at the mouth, for the air flow in and out of the plethysmograph lagged behind the flow at the mouth. This lag was confirmed by experiments in which normal adult subjects breathed in a Drinker respirator, the air flow being measured by a pneumotachograph connected to the outlet of the respirator. Simultaneous records of intra-oesophageal pressure and air flow obtained in this way were compared with similar tracings in which the air flow was recorded at the mouth, and it was found that the air flow in and out of the respirator not only lagged behind the flow at the mouth but also was of a different wave form and amplitude, the whole effect being one of damping.

The amount of lag in the body plethysmograph was measured by means of a model lung as shown in Fig. 2. A rubber anaesthetic bag was ventilated in the plethysmograph with tidal volumes of 26 and $13 \mathrm{ml}$. produced at various frequencies between 30 and 60 per minute by an electrically driven pump. 
The rate of air flow in and out of the bag was recorded by a pneumotachograph between the pump and the bag, and the air flow in and out of the plethysmograph by a pneumotachograph on the outlet of the box. The average lag of the plethysmograph record was 0.2 seconds behind the flow as measured directly. The amount of lag was virtually constant over the range of frequencies and tidal volumes investigated, and in analysing results a lag of 0.2 seconds has been assumed and allowed for.

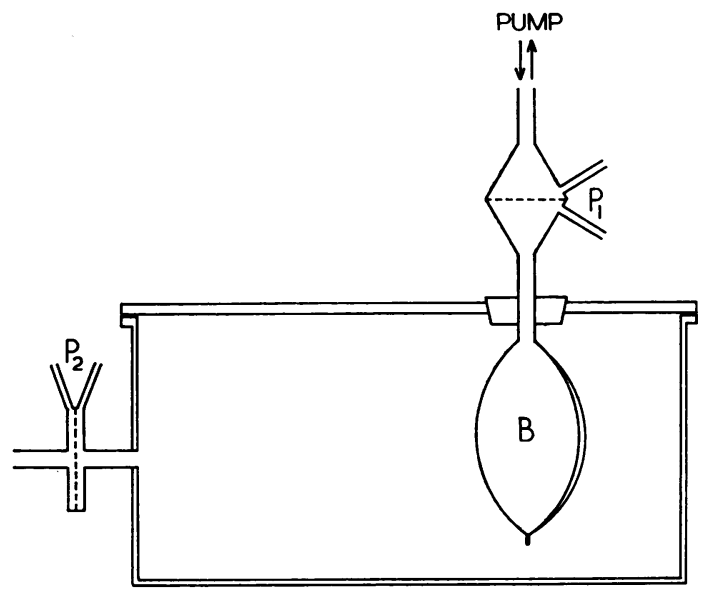

FIG. 2.-Diagram of model for measuring lag of body plethysmograph. $B$, rubber anaesthetic bag, $P_{1}$ pneumotachograph record ing direct flow, $P_{2}$ pneumotachograph recording plethysmograph flow.

\section{Procedure}

The babies were investigated as soon as possible after feeding without removing any of their clothes. The intra-oesophageal tube was usually introduced before placing the baby in the plethysmograph. With the baby in position and the rubber cuff inflated, the plethysmograph was tested for leaks by the method described by Cross (1949). Tracings were obtained as soon as the baby was breathing quietly, and no attempt was made to wait until the baby was asleep. The whole procedure presented no difficulties, since no greater discomfort was involved than with routine "tube feeding."

\section{RESUlts}

Twelve babies were investigated, and the results obtained are shown in Table I. A tracing of intraoesophageal pressure and air flow in a normal baby is shown in Fig. 3, together with the pressure volume diagram derived from one breath. Allowance has been made in Fig. 3 for the lag of the plethysmograph. It will be seen that in this case the proportion of the total work expended against elastic resistance is about the same as that found in adults. In the seven normal babies investigated the intra-oesophageal pressure swing was of the same order as that found in adults (about $5 \mathrm{~cm}$./ $\mathrm{H}_{2} \mathrm{O}$ ). When the baby cried, the intra-oesophageal pressure swing increased to about $50 \mathrm{~cm} . / \mathrm{H}_{2} \mathrm{O}$. The mean value of the minute volume in seven normal babies was $578 \mathrm{ml}$., and the work required to ventilate the lungs varied between 0.011 and $0.052 \mathrm{~kg} . \mathrm{m}$. $/ \mathrm{min}$. with a mean of $0.026 \mathrm{~kg} . \mathrm{m} . / \mathrm{min}$. The index of elastic resistance varied between 2.5 and $7.9 \mathrm{~cm}$. $\mathrm{H}_{2} \mathrm{O} / 10 \mathrm{ml}$. with a mean of $5.5 \mathrm{~cm}$. $\mathrm{H}_{2} \mathrm{O} / 10 \mathrm{ml}$.

The results in the two babies born by caesarean section fell within the normal range, but, in the two premature babies under $5 \mathrm{lb}$. in weight, the minute volume respired, the work of breathing, and the index of elastic resistance were all low. The findings in the third premature baby were of particular interest. This baby had suffered from asphyxia at birth, and when he was investigated at

TABLE I

RESULTS IN 12 NEWLY BORN BABIES

\begin{tabular}{|c|c|c|c|c|c|c|c|c|}
\hline Age in Days & $\begin{array}{c}\text { Birth } \\
\text { Weight } \\
\text { in lb. and oz. }\end{array}$ & $\begin{array}{l}\text { Weight in } \\
\text { lb. and oz. }\end{array}$ & $\begin{array}{c}\text { Respirations } \\
\text { per } \\
\text { Minute }\end{array}$ & $\begin{array}{l}\text { Tidal } \\
\text { Volume } \\
\text { in ml. }\end{array}$ & $\begin{array}{l}\text { Minute } \\
\text { Volume } \\
\text { in ml. }\end{array}$ & $\begin{array}{c}\text { Respiratory } \\
\text { Work in } \\
\mathrm{kg} \cdot \mathrm{m} . \mathrm{min} \text {. }\end{array}$ & $\begin{array}{l}\text { Index of } \\
\text { Elastic } \\
\text { Resistance } \\
\text { in cm. } \\
\mathrm{H}_{2} \mathrm{O}^{\prime} 10 \mathrm{ml}\end{array}$ & Diagnosis \\
\hline $\begin{array}{r}4 \\
6 \\
6 \\
7 \\
9 \\
11 \\
12\end{array}$ & $\begin{array}{lc}7 & 13 \\
6 & 13 \\
7 & 13 \\
6 & 4 \\
6 & 8 \\
6 & 8 \frac{1}{2} \\
6 & 14\end{array}$ & $\begin{array}{rr}7 & 5 \\
6 & 12 \\
7 & 8 \\
6 & 0 \\
6 & 11 \\
6 & 11 \\
6 & 14\end{array}$ & $\begin{array}{l}28 \cdot 5 \\
60 \\
44 \\
48 \\
43 \\
63 \\
37\end{array}$ & $\begin{array}{r}21.9 \\
11.3 \\
10.5 \\
9.2 \\
13.9 \\
9.7 \\
17.0\end{array}$ & $\begin{array}{l}623 \\
678 \\
465 \\
443 \\
598 \\
611 \\
628\end{array}$ & $\begin{array}{l}0.052 \\
0.029 \\
0.024 \\
0.011 \\
0.024 \\
0.025 \\
0.015\end{array}$ & $\begin{array}{l}4 \cdot 2 \\
5 \cdot 5 \\
7 \cdot 9 \\
5 \cdot 3 \\
6 \cdot 0 \\
7 \cdot 2 \\
2 \cdot 5\end{array}$ & $\begin{array}{c}\text { Normal } \\
\text {," } \\
\text {," } \\
\text {," }\end{array}$ \\
\hline $\begin{array}{r}3 \\
9 \\
11 \\
17 \\
21\end{array}$ & $\begin{array}{lc}6 & 13 \\
6 & 6 \\
4 & 3 \frac{1}{2} \\
4 & 3 \frac{1}{2} \\
4 & 12\end{array}$ & $\begin{array}{lc}6 & 6 \\
6 & 0 \\
4 & 7 \\
4 & 12 \frac{1}{2} \\
5 & 7 \frac{1}{2}\end{array}$ & $\begin{array}{l}51 \\
64 \\
56 \\
58 \\
49\end{array}$ & $\begin{array}{r}13 \cdot 1 \\
10 \cdot 8 \\
10 \cdot 1 \\
7 \cdot 0 \\
16 \cdot 8\end{array}$ & $\begin{array}{l}658 \\
671 \\
566 \\
405 \\
823\end{array}$ & $\begin{array}{l}0.035 \\
0.016 \\
0.010 \\
0.006 \\
0.031\end{array}$ & $\begin{array}{l}4 \cdot 8 \\
5 \cdot 4 \\
2 \cdot 8 \\
2 \cdot 7 \\
4 \cdot 7\end{array}$ & $\begin{array}{l}\text { Normal, caesarean section } \\
\text {,", } \\
\text { Premature } \\
\text { Premature, asphyxia, } \\
\text { Cheyne-Stokes breat hing }\end{array}$ \\
\hline
\end{tabular}



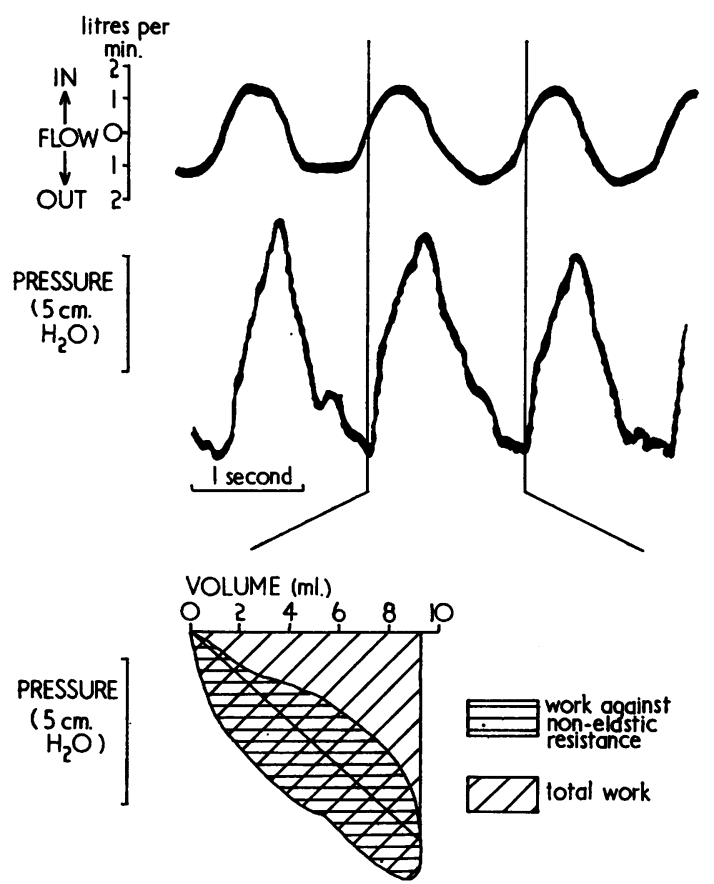

Fig. 3. - Tracing of intra-oesophageal pressure and air flow in a normal newborn baby. The pressure volume diagram derived from one breath is shown below. The flow tracing has been corrected for lag.

an age of 21 days the tracings showed CheyneStokes breathing. Both the intra-oesophageal pressure and air waxed and waned, as shown in Fig. 4. It will be seen that the respiratory rate was slower when respiration was shallow and more rapid during the deeper breaths. The length of a complete cycle of periodic breathing was about 15 seconds.

\section{Discussion}

From our results, the work in kg.m./min. required to ventilate the lungs in newly born babies is about one-tenth of that required in adults. The respiratory rate in newborn babies is about three times the adult figure, so that the work per breath in infants is about one-tenth of that found in adults. The intrathoracic pressure fluctuations are about the same in babies and adults, indicating that the force applied per unit of area is of the same order in both. The values for tidal volume and minute volume respired that we have obtained in normal babies are about the same as those reported by other workers, but it seems probable that they may be falsely low because of artefacts due to the use of a body plethysmograph, which gives too low a tidal volume because there is some loss of energy in compressing the air in the plethysmograph. As a result of the lag of the plethysmograph and the possible errors in its assessment, it is likely that the measurement of the work of breathing and its separation into its elastic and non-elastic components are less accurate than similar measurements in adults.

The type of Cheyne-Stokes breathing observed is probably central in origin. The changes in intra-oesophageal pressure and air flow suggest a periodic waxing and waning in the respiratory centres discharge rather than waxing and waning pulmonary congestion.

It has been shown by Marshall, Mcllroy, and Christie (1954) and Marshall and Christie (1954) that the rate and depth of breathing in patients with heart disease and pneumonia are adjusted so that the metabolic needs of the body are met with the minimum expenditure of respiratory work. It would clearly be of interest to know whether a

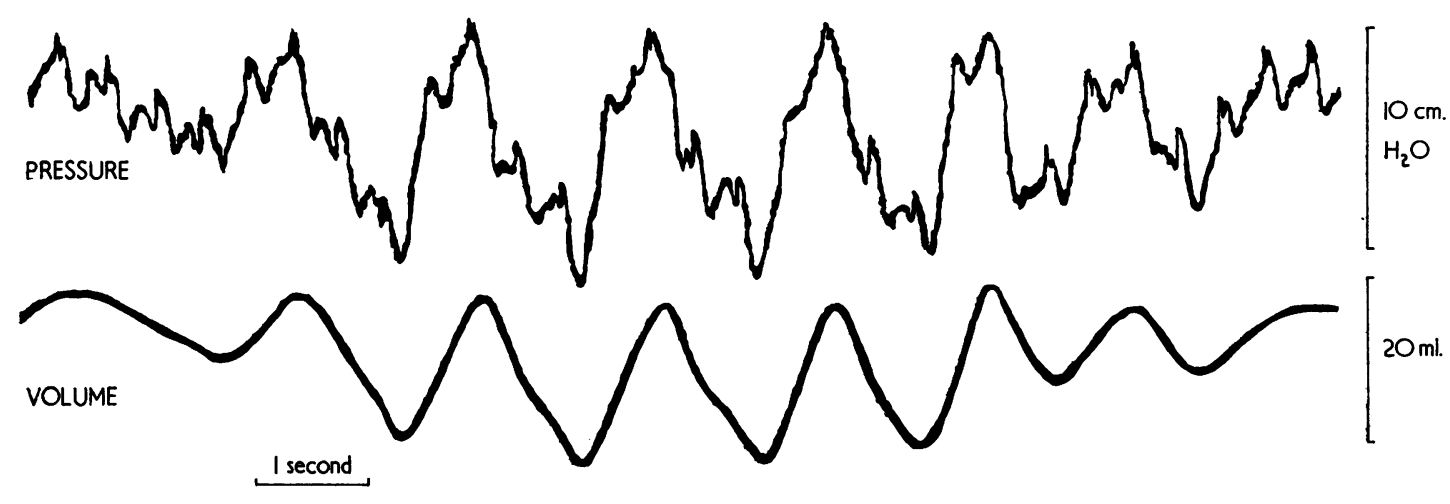

FIG. 4.-Tracing of intra-oesophageal pressure and tidal volume in a baby with Cheyne-Stokes breathing. 
similar state of affairs exists in newly born babies who also breathe more rapidly. The respiratory rate at which the work of breathing is minimal depends principally on the balance of the elastic and non-elastic resistances encountered in ventilating the lungs. It was felt that the errors due to the lag of the plethysmograph and the difficulties involved in measuring dead space in infants precluded any detailed analysis. It was found, however, that, in infants breathing at a rate of 40 to 50 per minute, the proportion of the total work of ventilating the lungs expended against elastic resistance was about the same as that in adults breathing at a rate of about 15 per minute. Since the balance of the elastic and non-elastic resistances is the same in adults and infants at the normal rate of breathing, it seems reasonable to suppose that in infants, as in adults, the rate and depth of breathing are so adjusted that respiratory work is minimal.

\section{SUMMARY}

The mechanical work required to ventilate the lungs of newly born babies has been measured from simultaneous records of intra-oesophageal pressure and air flow using a body plethysmograph. The mean work of breathing in normal babies is $0.026 \mathrm{~kg} . \mathrm{m} . / \mathrm{min}$. ; this is about $10 \%$ of the adult value.

The intrathoracic pressure swing in babies is about the same as that found in adults.

It is suggested that in infants as in adults the rate and depth of breathing are adjusted so that the metabolic needs are met with a minimal expenditure of respiratory work.

\section{RefERENCEs}

Boutourline-Young, H. J., and Smith, C. A. (1950). Amer. J. Dis. Child., 80, 753.

Cross, K. W. (1949). J. Physiol., Lond., 109, 459.

Dornhorst, A. C., and Leathart, G. L. (1952). Lancet, 2, 109.

Fry, D. L., Stead, W. W., Ebert, R. V., Lubin, R. I., and Wells, H. S. (1952). J. Lab. clin. Med., 40, 664.

Lilly, J. C. (1950). Meth. med. Res., 2, 131.

McIlroy, M. B., Marsha!l, R., and Christie, R. V. (1954). Clin. Sci., $13,127$.

Marshall, R., and Christie, R. V. (1954). Itid., 13, 403. McIlroy, M. B., and Christie, R. V. (1954). Ibid., 13, 137

Mead, J., and Whittenberger, J. L. (1953). J. appl. Physiol., 5, 779. Murphy, D. P., and Thorpe, E. S. (1931). J. clin. Invest., 10, 545.

Shaw, L. A., and Hopkins, F. R. (1931). Amer. J. Dis. Child., 42, 335. 